\title{
Design of Environmental Pollution Monitoring Tool Based on Internet of Things (IoT)
}

\author{
Febrin Aulia Batubara ${ }^{1, *}$ Bakti Viyata Sundawa ${ }^{1}$ Meidi Wani Lestari ${ }^{1}$
}

\author{
${ }^{1}$ Electrical Engineering Department, Politeknik Negeri Medan, 20155, Indonesia \\ *Corresponding author. Email: febrinbatubara@polmed.ac.id
}

\begin{abstract}
Monitoring of environmental pollution level on campus is very important to do. According to UI Green Metric 2018 data, there are 719 campuses to participate in the developing of green campus and issues of sustainability. One of assessment is implementation of smart system to solve environmental problems in the campus area. To develop an environmental pollution monitoring tool based on IoT needs hardware and software. The hardware consists of sensors namely dust particle of PM-2.5 sensor type GPY21010AU0F, temperature and humidity sensor type SHT11, light intensity sensor type BH1750, CO2 sensor type MG-811, SIM 800, ADC module and microcontroller ESP32. Software is done using PHP and database. Parameters to be measured are density of dust particle, temperature, humidity, light intensity, $\mathrm{CO} 2$ level and loudness. Furthermore, information about environmental pollution data can be displayed and accessed in real-time via smartphones and computers. The sensors read the value every in 5 seconds. The results is in average value, density of dust particle is $1.39 \mu \mathrm{g} / \mathrm{m} 3$. Temperature is $36.580 \mathrm{C}$. Humidity is $53.80 \% \mathrm{RH}$. Light intensity is 10,613 lux. CO2 level is $15.50 \mathrm{ppm}$ (parts per million). There is upper threshold value for temperature and humidity. Others, it is a normal condition and no pollution because campus is still in lockdown.
\end{abstract}

Keywords: Internet of Things (IoT), Sensors, Green Campus.

\section{INTRODUCTION}

Monitoring of environmental pollution level on campus is very important to do. According to UI Green Metric 2018 data, there are 719 campuses to participate in the developing of green campus and issues of sustainability [1]. One of assessment is implementation of smart system to solve environmental problems in the campus area.

Previous research about this case has done by title "Development of Environmental Temperature Monitoring Based on Internet of Things (IoT)" [2], "Smart Home Development with Microcontrollers ESP32 Dan MC-38 Door Magnetic Switch Sensor Based on Internet of Things (IoT)" [3] and "Application of Microcontroller Interfacing Trainer Based on Internet of Things Based Using ESP32 in Interfacing Subject" [4]. In previous research, they are all to use ESP32 for IoT application because ESP32 is a series of low-cost and low-power and be developed with integrated $\mathrm{Wi}-\mathrm{Fi}$ and dual Bluetooth modes [5],[6]. But it related to environmental data only performed on one parameter measuring namely temperature.
In this research, there are several parameters to be measured namely that density of dust particles, humidity, temperature, light intensity, $\mathrm{CO}_{2}$ levels and loudness. Furthermore, information about environmental pollution data can be displayed and accessed in real-time via smartphones and computers.

To develop an environmental pollution monitoring tool based on IoT needs hardware and software. The hardware consists of sensors, SIM 800, ADC module and microcontroller ESP32. Software is done using PHP and database. The tool will be installed in campus of Politeknik Negeri Medan (Polmed). This is for preparation of green campus development.

\section{METHOD}

The following is a block circuit diagram of Environmental Pollution Monitoring Tool as shown in Figure 1. The device consists of hardware and software. The hardware consists of sensors namely dust particle of PM-2.5 sensor type GPY21010AU0F, temperature and humidity sensor type SHT11, light intensity sensor type $\mathrm{BH} 1750, \mathrm{CO}_{2}$ sensor type MG-811 and loudness sensor, 
SIM 800, ADC module and microcontroller ESP32.. Software is programming based on Web using PHP, database and Grafana Template.
Furthermore, based on the block diagram scheme, it is implemented into the circuit scheme as shown in Figure 2.
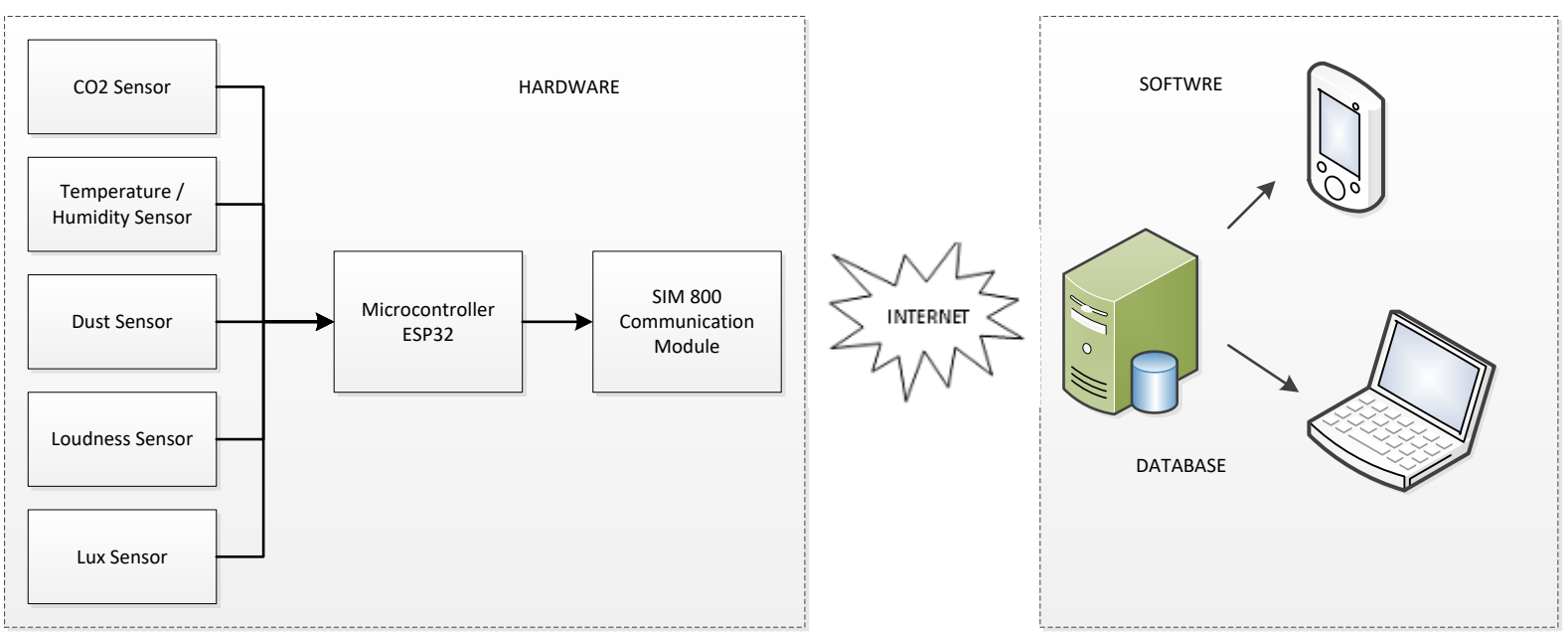

Figure 1 Block diagram
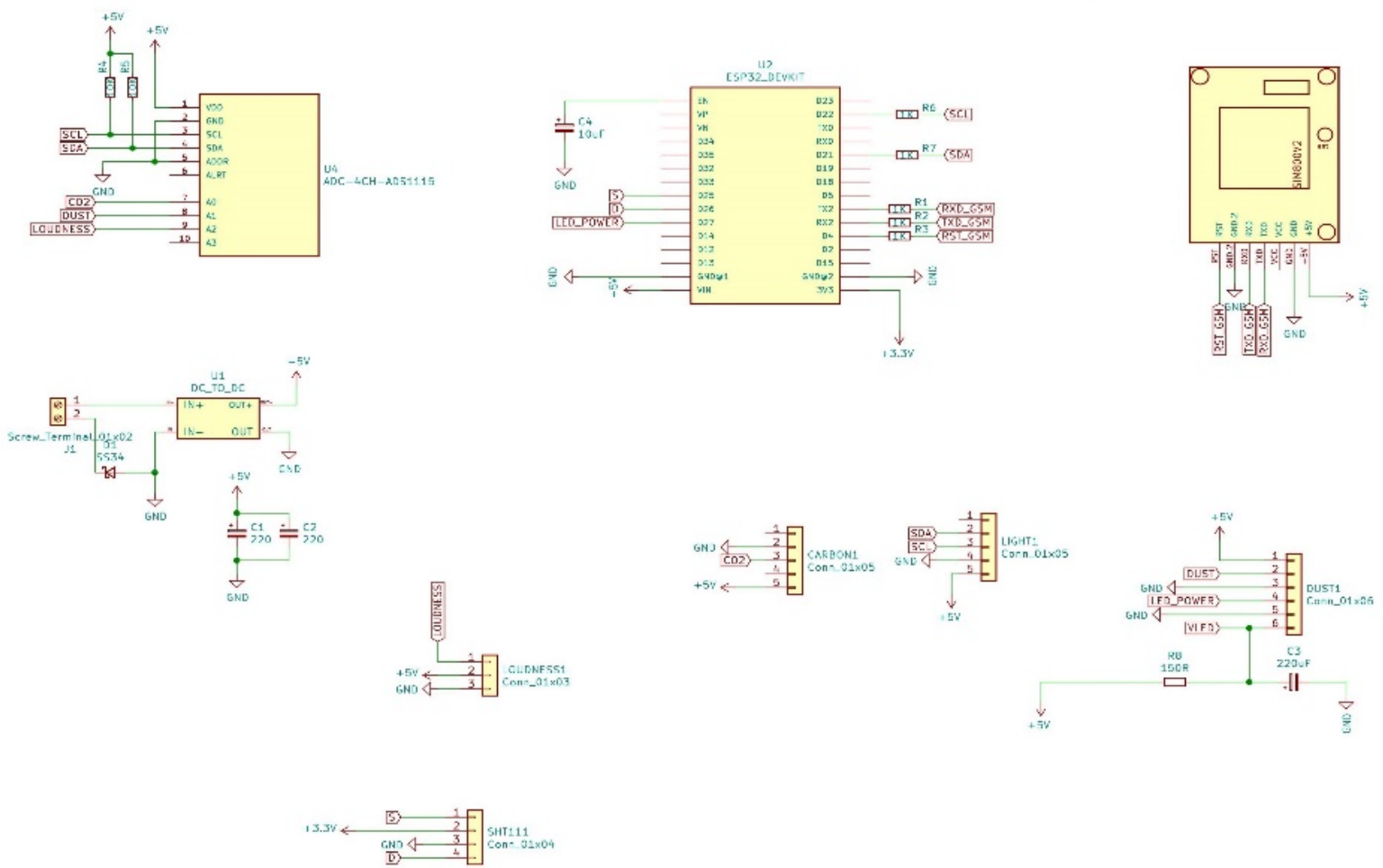

Figure 2 Circuit scheme

Work process of the system is divided into three block sections, namely data acquisition, transmit and monitoring. Parameters to be measured are density of dust particle, temperature, humidity, light intensity, $\mathrm{CO}_{2}$ level and loudness. The sensors read the value in units of quantity respectively. Density of dust particle is in $\mu \mathrm{g} / \mathrm{m}^{3}$. Temperature is in ${ }^{0} \mathrm{C}$. Humidity is in $\% \mathrm{RH}$. Light intensity is in lux. $\mathrm{CO}_{2}$ level is in ppm (parts per million).
Loudness is in dB. Explanation about workflow systems detailed is presented in Figure 3.

Installation of sensors in the microcontroller ESP32 requires knowledge sensors hardware. Output of dust particle sensor, $\mathrm{CO}_{2}$ sensor and loudness sensor are still analog. We need analog to digital converter (ADC) type ADS1115 to convert it. Explanation about circuit scheme detailed is presented in Figure 4. 


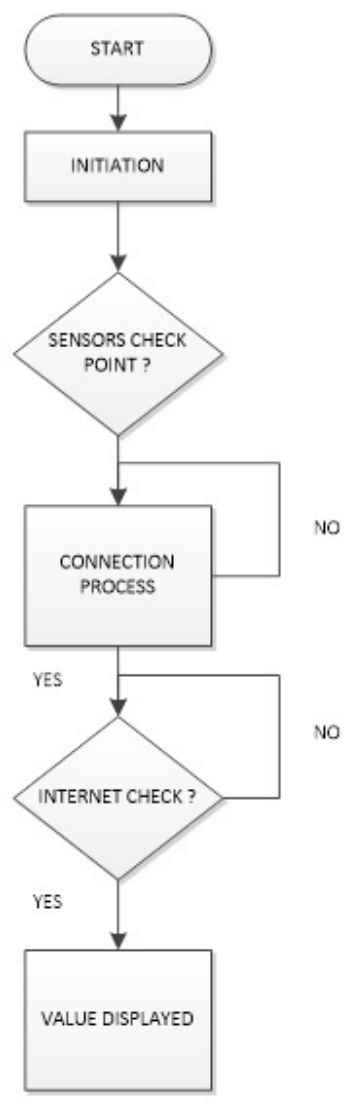

Figure 3 Flowchart

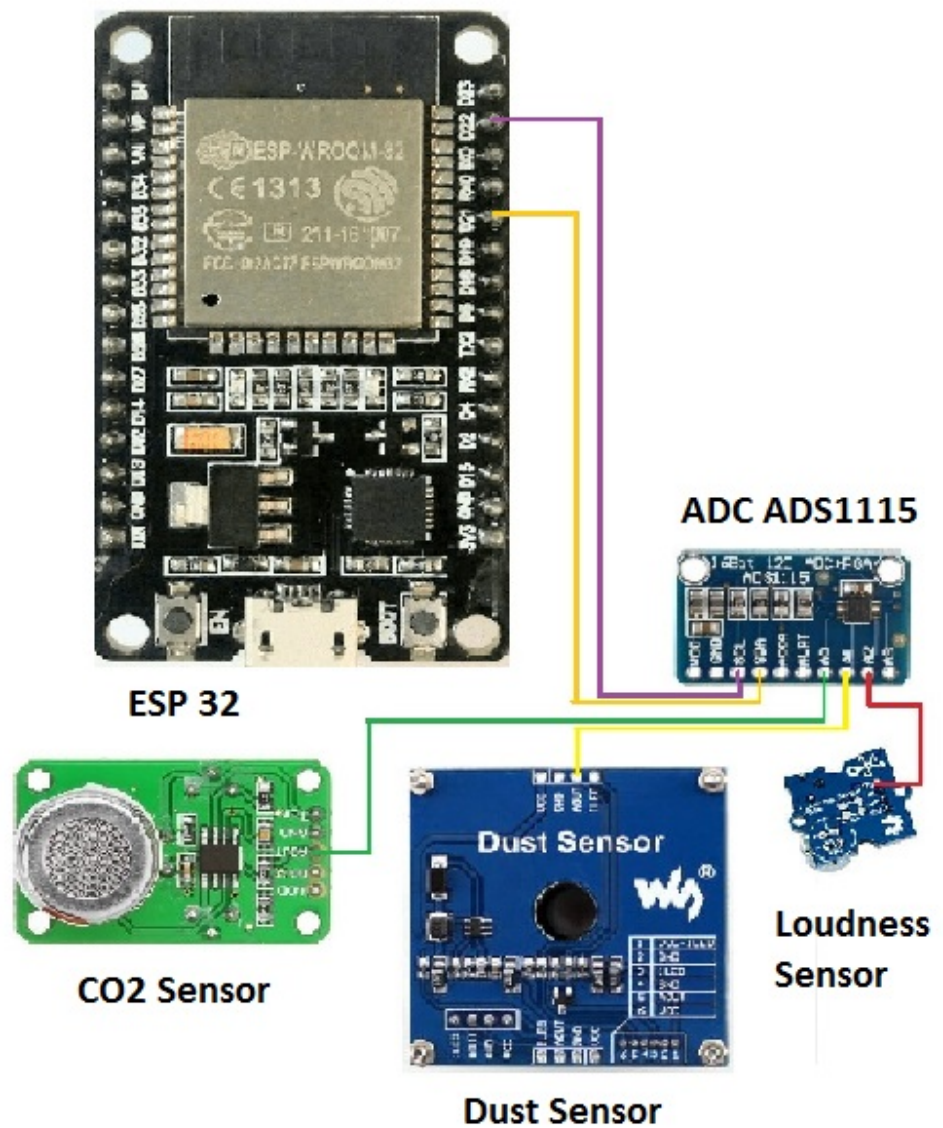

Figure 4 Circuit scheme ADC
All scheme components required power supply stable for smooth acquisition. If it happens problems in the power supply, then the reading of the sensor value becomes error, and the reading process will be carried out repeat until a certain value is obtained.

Measured data of sensors can be taken within a range in 5 seconds. It is programmed in microcontroller ESP32. Measured data are transferred to the web server. This research uses Virtual Private Server (VPS) as web server.
Communication system uses SIM 800 communication module to connect to web server. Internet connectivity checks will always check continuously to ensure that tool is always connected.

Measured data is done in campus and the results is presented in Grafana Load Database Template as shown in Figure 5. This form will be displayed on the user's smartphone or PC.

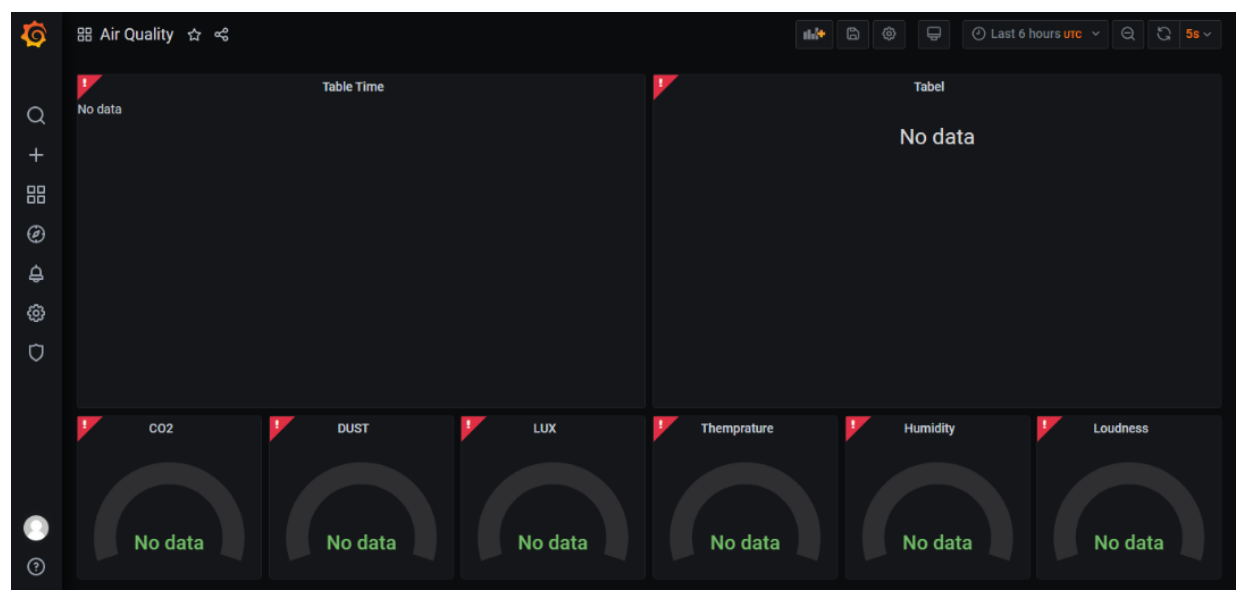

Figure 5 Grafana load database template 


\section{RESULT AND DISCUSSION}

Measured data results are presented as shown in Figure 6, Figure 7, Figure 8, Figure 9, Figure 10 and Figure 11.

Hardware module is developed by sensors, SIM 800, ADC module and microcontroller ESP32. Sensors is an automatic term that refers to the ability to diagnose data on environment. Sensors provide data to microcontroller ESP32. However, data from output of dust particle sensor, $\mathrm{CO}_{2}$ sensor and loudness sensor are still analog. We need analog to digital converter (ADC) to convert it.

SIM 800 is used for communication module. This module is a complete Quad-Band $850 / 900 / 1800 / 1900 \mathrm{MHz}$ GSM/GPRS. SIM 800 will send data from microcontroller ESP32 to Virtual Private Server (VPS).

Measurement data results must be compared with regulation standards set by the government. This is to find out whether the environmental conditions are normal or dangerous.

Standard Regulations by Indonesian Government:

1. Regulation of Environmental Ministry No.12/2010 [7] : a. Density of dust particle PM-2.5 max. 66 $\mu \mathrm{g} / \mathrm{m}^{3}$

b. $\mathrm{CO}_{2}$ level max. $3180 \mathrm{ppm}$

2. Regulation of Health Ministry No.70/2016 [8] : light intensity min. 150 lux

3. Regulation of Manpower and Transmigration Ministry No.13/2011 [9] : loudness max. 97 dB

4. Regulation of Manpower, Transmigration and Cooperation Ministry No.1/1978 [10] : temperature $26^{\circ} \mathrm{C}-30^{\circ} \mathrm{C}$ and humidity $65 \%$ $95 \%$.

According to measured data results in Table 1. The results is in average value, density of dust particle is 1.39 $\mu \mathrm{g} / \mathrm{m}^{3}$. Temperature is $36.58{ }^{\circ} \mathrm{C}$. Humidity is $53.80 \% \mathrm{RH}$. Light intensity is 10,613 lux. $\mathrm{CO}_{2}$ level is $15.50 \mathrm{ppm}$ (parts per million). There is upper threshold value for temperature and humidity. Others, it is a normal condition and no pollution because campus is still in lockdown.

Temperature, humidity and light intensity are parameters that they are not affected by lockdown condition. Many application on smartphone that can be comparison for temperature measurement such as 'cuaca' as shown in Figure 12.

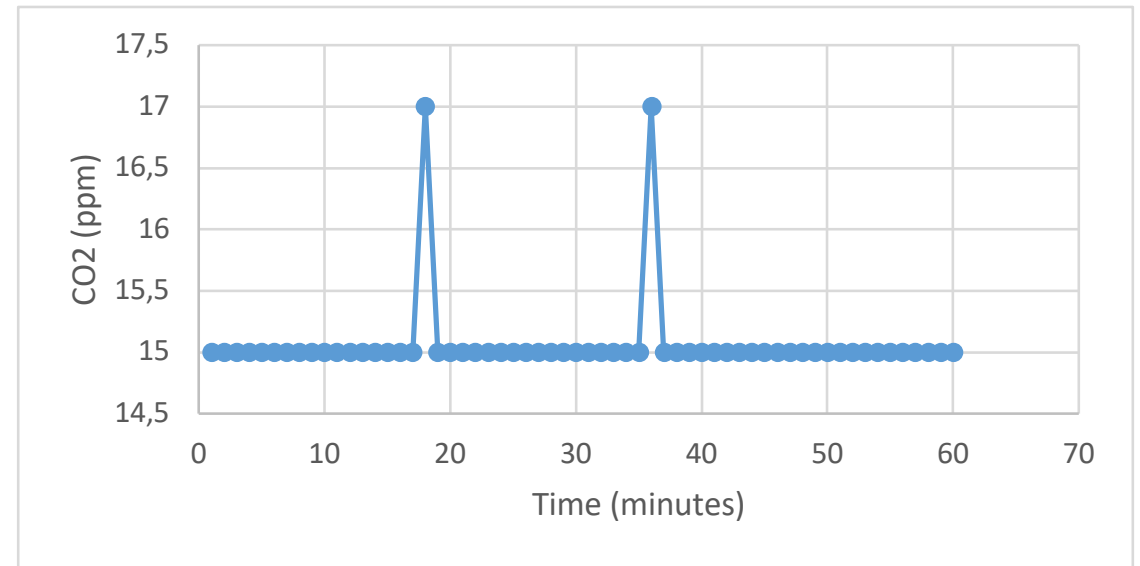

Figure $6 \mathrm{CO}_{2}$ measured data

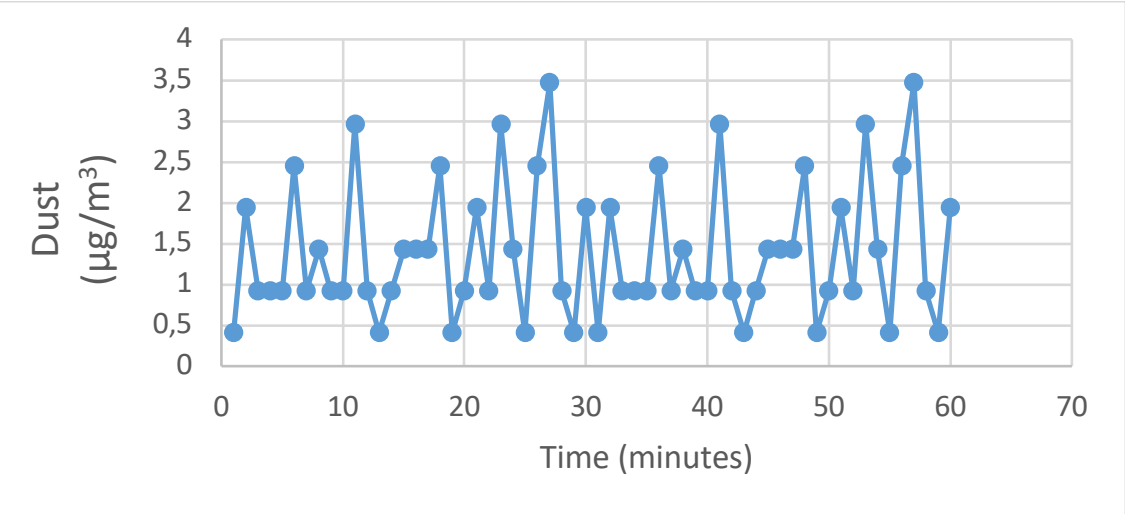

Figure 7 Dust measured data 


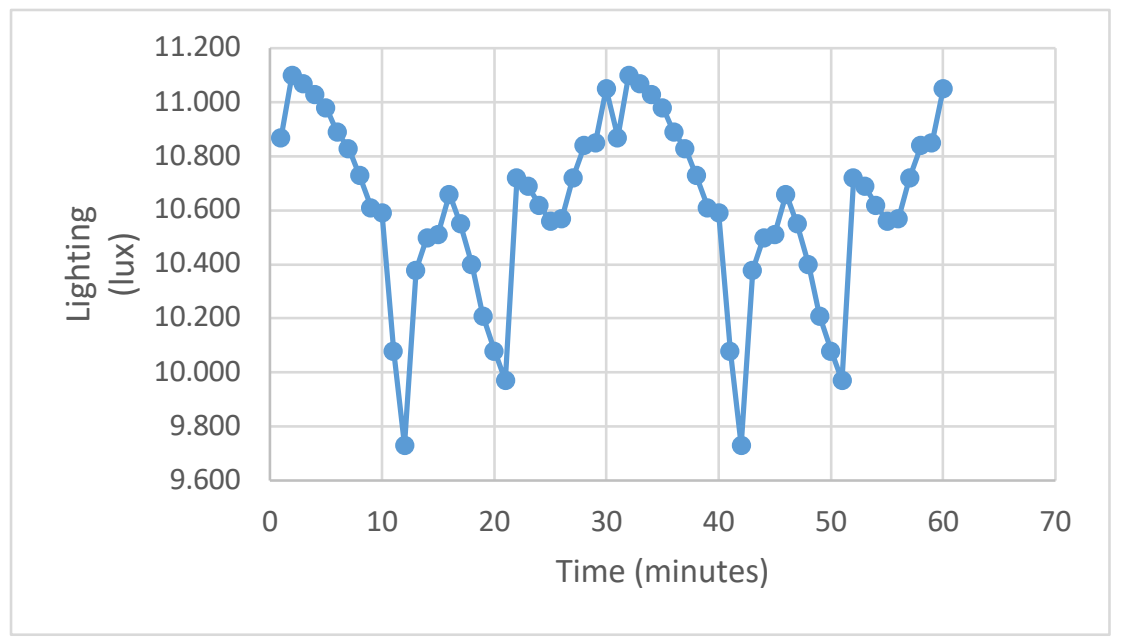

Figure 8 Lighting measured data

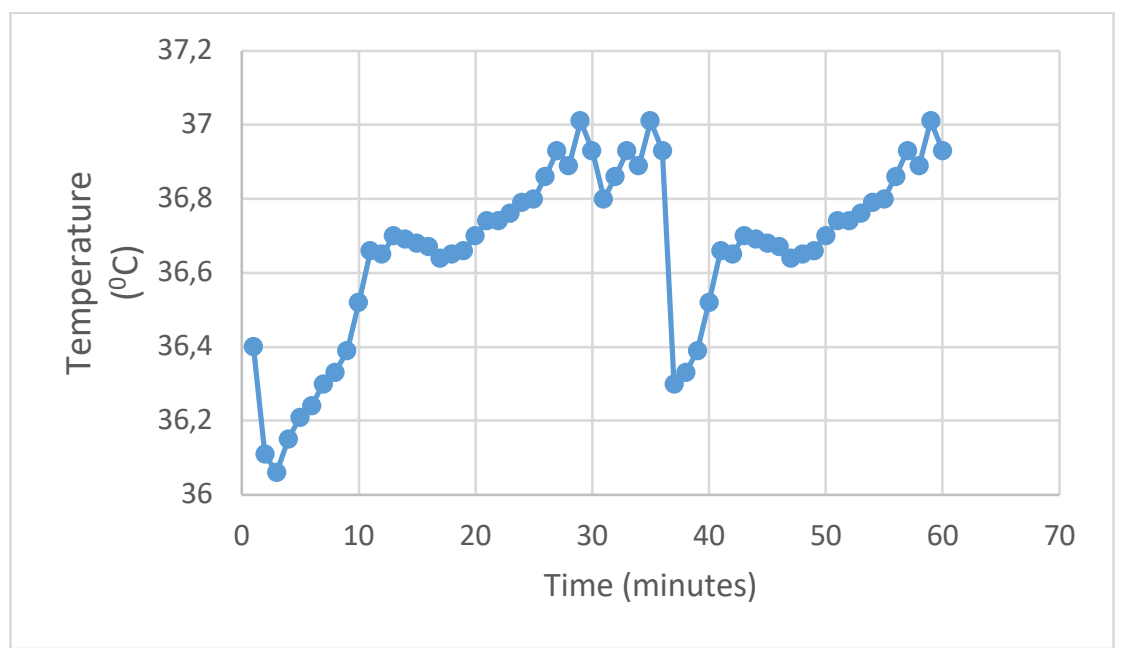

Figure 9 Temperature measured data

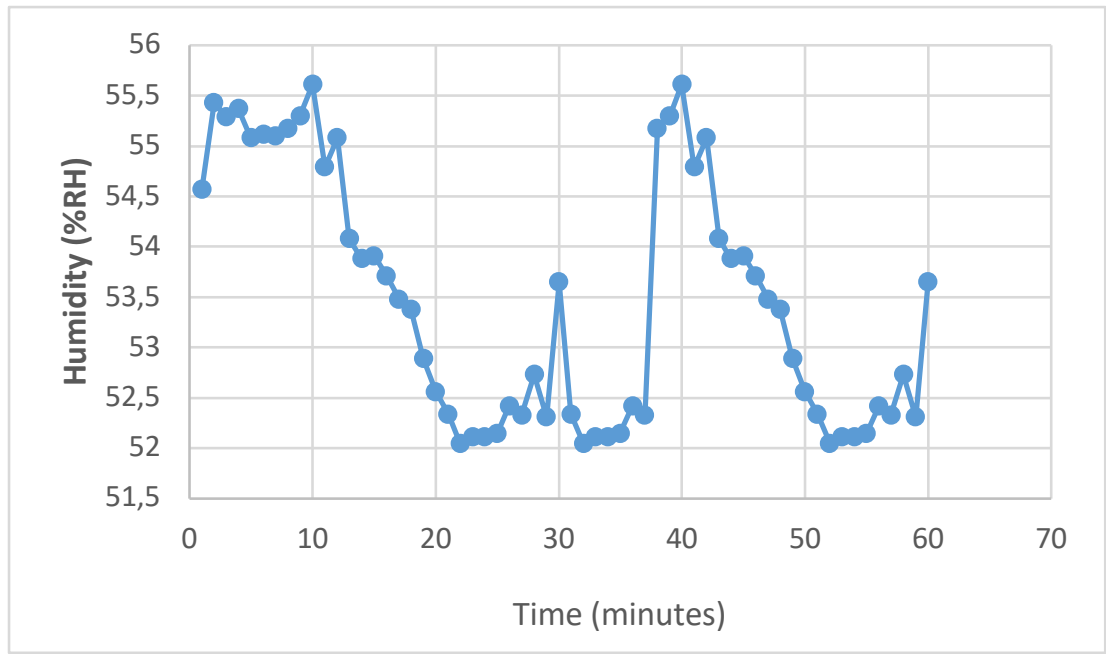

Figure 10 Humidity measured data 


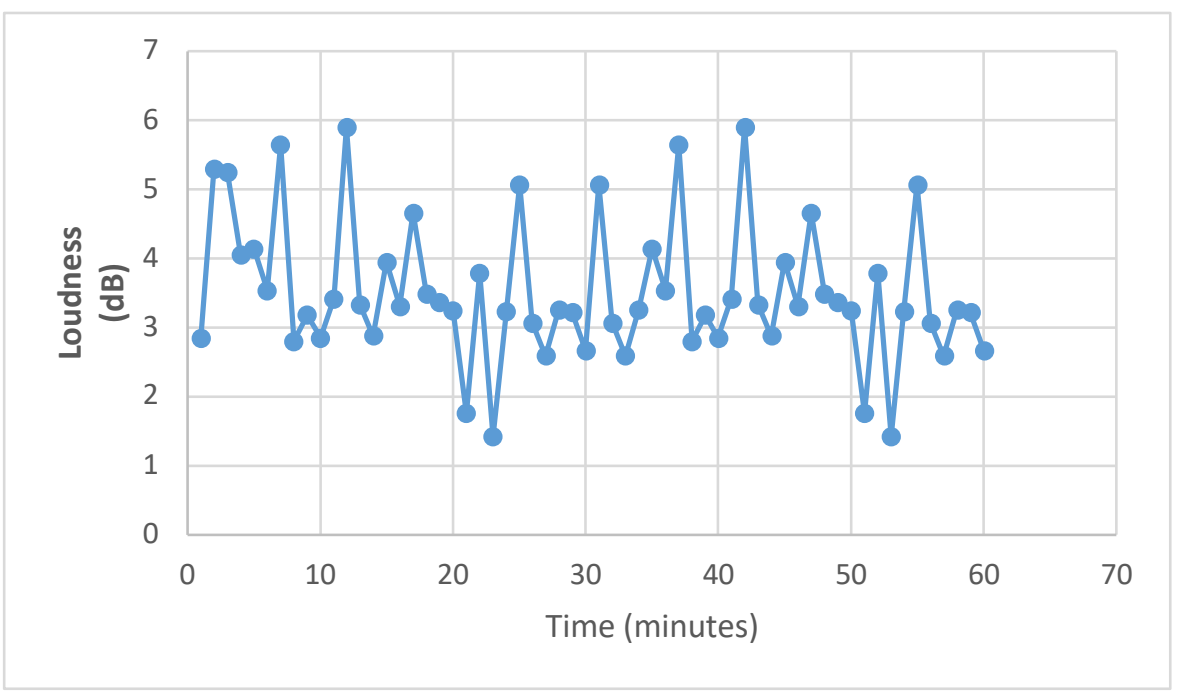

Figure 11 Loudness measured data

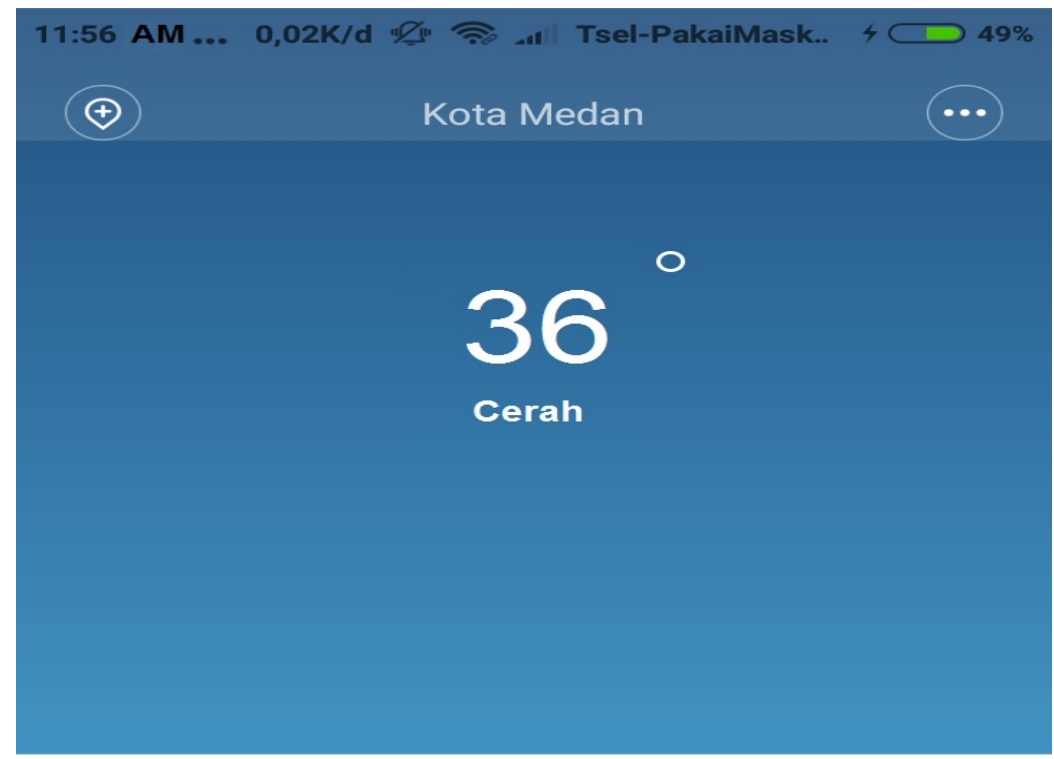

Figure 12 'Cuaca' application

\section{CONCLUSION}

We have successfully designed a environmental pollution monitoring tool based on IoT. The tool density of dust particles, humidity, temperature, light intensity, $\mathrm{CO}_{2}$ levels and loudness and user information about environmental pollution via smartphones and computers. The tool becomes one of instrumentation for preparation of green campus development. In addition, it can also provide more sensors and integrated with camera for future experiments. So that more environmental parameters will be measured.

\section{ACKNOWLEDGMENT}

Authors wishing to acknowledge DIPA of Politeknik Negeri Medan and Ministry of Research, Technology and Higher Education (Kemenristekdikti) Indonesian Government who funded this research through scheme of Penelitian Multi Disiplin Ilmu (PMDI) 2020 contract number: B/218/PL5/PT.01.05/2020.

\section{REFERENCES}

[1] University of Indonesia, "Sustainable University in a Changing World : Lessons, Challenges and Opportunities,“ Journal of UI GreenMetric World University Rankings, 2019.

[2] Y. A. Suryo, "Design of Portable Environmental Temperature Monitoring Based on Internet of Things," Cyclotron, vol. 2, no. 2, 2019.

[3] A. Setiawan and A. I. Purnamasari, "Smart Home Development with ESP32 Microcontrollers and MC-38 Door Magnetic Switch Sensor Based on Internet of Things (IoT) to Improve Early Detection 
of Housing Security," Journal of RESTI, vol. 3, no. 3, pp. 451 - 457, 2019.

[4] H. Kusumah and R. A. Pradana, "Application of Microcontroller Interfacing Trainer Based on Internet of Things Using ESP 32 in Interfacing Subject," Journal of Cerita, vol. 5, no. 2, 2019.

[5] Espressif System, "ESP32 Series Datasheet," Espressif Inc., 2019.

[6] Kolban, "Kolban's Book on ESP32," https://leanpub.com/kolban-ESP32.M, 2017.

[7] Ministry of Environment Indonesian Republic, "Ambient Air Quality Standards," Regulation of Environment Ministry No.12, 2010.
[8] Ministry of Health Indonesian Republic, "Light level requirements in traffic zones and public areas," Regulation of Health Ministry No.70, 2016.

[9] Ministry of Manpower and Transmigration Indonesian Republic, "Noise Threshold Value," Regulation of Manpower and Transmigration Ministry No. 13, 2011.

[10] Ministry of Manpower, Transmigration and Cooperation Indonesian Republic, "Temperature and Humidity Threshold Value," Regulation of Manpower, Transmigration and Cooperation Ministry No. 1, 1978. 